\title{
Sabiaceae endémicas del Perú
}

\section{Blanca León ${ }^{1,2}$}

${ }^{1}$ Museo de Historia Natural, Av. Arenales 1256, Aptdo. 14-0434, Lima 14, Perú

2 Plant Resources Center, University of Texas at Austin, Austin TX 78712 EE.UU.

blanca.leon@mail.utexas.edu

\section{Resumen}

La familia Sabiaceae es reconocida en el Perú por presentar dos géneros y 19 especies (Brako \& Zarucchi, 1993; Ulloa Ulloa et al., 2004), todas árboles. En este trabajo reconocemos cuatro endemismos en el género Meliosma. Los taxones endémicos provienen de la región Bosques Muy Húmedos Montanos, entre los 1600 y 2550 m de altitud. Tres especies se encuentran representadas dentro del Sistema Nacional de Áreas Naturales Protegidas por el Estado.

Palabras claves: Sabiaceae, Meliosma, Perú, endemismo, plantas endémicas.

\section{Abstract}

The Sabiaceae are represented in Peru by two genera and 19 species (Brako \& Zarucchi, 1993; Ulloa Ulloa et al., 2004), all trees. Here we recognize four endemic species in the genus Meliosma. These endemic species are found in Very Humid Montane Forests region, between 1600 and 2550 m elevation. Three species have been recorded within Peru's protected areas system.

Keywords: Sabiaceae, Meliosma, Peru, endemism, endemic plants.

\section{Meliosma pumila A.H. Gentry}

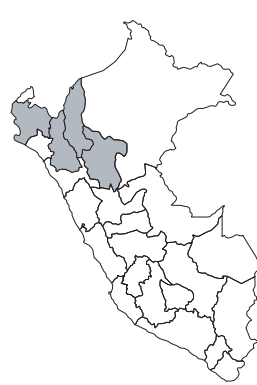
$2550 \mathrm{~m}$.
Publicación: Novon 2(2): 155. 1992. Colección tipo: D.N. Smith \& R. Vásquez 4894 Herbarios: MO; AMAZ!, USM. Nombre común: Desconocido. Registro departamental: AM, CA, SM. Regiones Ecológicas: BMHM; 1600-

SINANPE: PNC, PNRA, ZRCC

Herbarios peruanos: AMAZ (isotipo), HUT (1), USM (isotipo citado).

Observaciones: Arbusto conocido de varias poblaciones aisladas, en el nor-oriente del país, en las cuencas del Chiriaco y Montecristo. Dos poblaciones, incluyendo la del Parque Nacional Río Abiseo coinciden con el área conocida para otras especie endémica, el mono choro de cola amarilla (Lagotbrix flavicauda). Meliosma pumila se conoce también de zonas con endemismo alto como en la Zona Reservada Cordillera Colán. Amenazas a sus poblaciones, en especial para las que se ubican fuera de áreas protegidas, provienen de la deforestación e incendios intencionales.

\section{Meliosma simiarum A.H. Gentry}

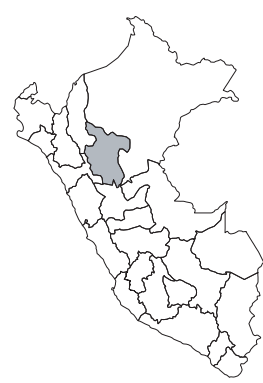

\section{EN, B1ab(iii)}

Publicación: Novon 2(2): 155. 1992. Colección tipo: A.H. Gentry \& D.N. Smith 45225

Herbarios: MO, NY; USM.

Nombre común: Desconocido.

Registro departamental: SM.

Regiones Ecológicas: BMHM; 1850$2040 \mathrm{~m}$.

SINANPE: Sin registro.

Herbarios peruanos: AMAZ (1), USM (isotipo citado).

Observaciones: Árbol pequeño, conocido de la cuenca alta del Mayo. Al igual que Meliosma pumila, parte de su rango de distribución coincide con la del mono choro de cola amarilla, una especie endémica. Amenazas a sus poblaciones provienen de la deforestación, con fines madereros o agrícolas.

\section{Meliosma sirensis A.H. Gentry}

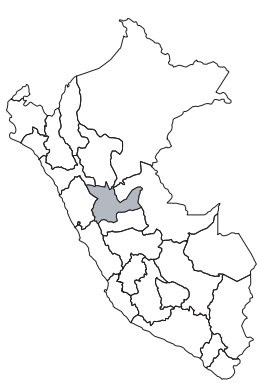

\section{CR, B1ab(iii)}

Publicación: Novon 2(2): 157. 1992.

Colección tipo: B. Wallnöfer 11-23778

Herbarios: MO; USM.

Nombre común: Desconocido.

Registro departamental: HU.

Regiones Ecológicas: BMHM; $1750 \mathrm{~m}$.

SINANPE: RCS

Herbarios peruanos: USM (isotipo citado).

Observaciones: Árbol pequeño, conocido de una localidad, en la Serranía del Sira, en la cuenca del Pachitea. Esta localidad forma parte de la Reserva Comunal El Sira, sin embargo amenazas por deforestación subsisten.

\section{Meliosma youngii A.H. Gentry}

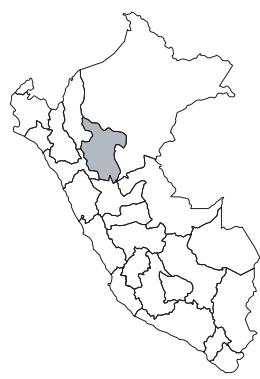

\section{EN, B1ab(iii)}

Publicación: Novon 2(2): 157. 1992.

Colección tipo: K.R. Young 4070

Herbarios: F, MO; HUT!.

Nombre común: Desconocido.

Registro departamental: SM.

Regiones Ecológicas: BMHM; $2350 \mathrm{~m}$. SINANPE: PNRA

Herbarios peruanos: HUT (isotipo).

Observaciones: Árbol de sotobosque, conocido de la localidad tipo, en la cuenca del Montecristo, un tributaro del Huallaga. Esta especie no ha vuelto a ser recolectada, si bien se han realizado otras expediciones botánicas al área. 